\title{
Obituary
}

\section{Paul Patnleve}

$\mathrm{W}^{\mathrm{n}}$ HEN I went to see him shortly before his untimely death, Prof. Paul Painleve was editing, with the aid of an assistant, the second part of his famous lectures on the "Mécanique des Fluides" recently delivered at the Sorbonne. In the dusk of his life, the 'President', as he was familiarly called by his friends, was thus returning to his favourite studies, for it was as a mathematician that M. Painleve began his extraordinary career. He was slowly recovering from a long and dangerous breakdown and was hoping to give an inaugural lecture in the great hall of the Conservatoire des Arts et Métiers, which was recently named after him in honour of his scientific genius. The hope was not to be fulfilled: instead, it was his coffin which was placed in that very hall before it was borne to the Panthéon. "I am still holding on to life," he was heard to say recently ; "and if I have to let go, I shall try to do it as elegantly as I can!" These prophetic words became true when on October 29, Prof. Painlevé died in his own home from heart failure. In him, France loses one of her most distinguished sons, and the world one of the greatest mathematicians and statesmen of the day.

Painleve's political career, which culminated in his being Prime Minister of France on three occasions, was a vital part of the Third Republic and of contemporary history. Born in Paris on December 5, 1863, of a modest family, Paul Painlevé, after a brilliant academic career, made his first appearance in public life at the time of the Dreyfus affair when, at the risk of losing his appointment, he took sides with the Radicals. In 1908, he started active propaganda for the organisation of military aviation. From his election to the Chamber of Deputies in 1910, Paul Painleve was constantly in the public eye. When War broke out, he became head of the Inventions Commission of the Chamber, taking a personal interest in all the plans and models submitted to his department. In October 1915, he was entrusted with the Ministry of Inventions; and two years later he was given the portfolio of Minister of War in M. Ribot's administration, only to take over from him, soon after, the reins of government.

In 1924 Painlevé was elected president of the Chamber of Deputies; soon after, he was chosen by the Left parties as their candidate for the presidency of the French Republic, but was narrowly defeated by $M$. Doumergue. In the rapid succession of governments which followed the fall of M. Herriot's administration, Paul Painlevé was twice Prime Minister, in which capacity he attended the momentous meetings of the League of Nations Council in 1925 when the Locarno Treaties were drafted. His wide political experience and his sense of realities had no doubt an important influence on the issues at stake. In all the subsequent administrations but one, Paul Painlevé held office as War Minister or Air Minister, an appointment always close to his heart. Public service, however, taxed his health to the utmost. A year ago, the 'President' collapsed in the Chamber during the fateful discussion of the "Aéropostale" and never recovered full vigour.

Paul Painlevé was well known in scientific circles in England. He had lectured at the Royal Institution on "Modern Conceptions of Matter and Classical Science"; and the University of Cambridge conferred on him the honorary degree of Doctor of Science. He was also an honorary member of the London Mathematical Society. In the international field, however, he was known not only as president of the International Committee of Intellectual Co-operation, but also as a scholar and a mathematician of the first rank, in which capacity he received many honours from the principal learned institutions of the world. Indeed, Paul Painlevé began his public life as professor of mechanics in the University of Lille at the age of twenty-three years, in 1886, being appointed soon after to the Sorbonne and the Ecole Polytechnique. His first important work was his thesis on "The Singular Lines of Analytical Functions" (1887), in which he investigated a function in the neighbourhood of a singular line. Such cases arise in the discussion of Cauchy's integral or again in Taylor's series when it is convergent in a certain circle. Weierstrass, Tannery, Appell and Hermite have discussed similar cases. Painlevé's treatment of the question led him to the following important theorem : "When a series $F=\Sigma V_{n}(x, y)$ converges uniformly on the contour $s$ of a closed area $S$, in the interior of which the functions $V_{n}(x, y)$ are regular and satisfy the equation $\Delta V_{n}=0$, then the series $F$ converges uniformly in $S$, and the series formed by the derivatives of its terms converge uniformly in any area $S^{\prime}$ interior to $S$ but without any common point with $s$, and represent the derivatives corresponding to $F$." $\mathrm{He}$ showed further that singular lines may be 'artificial' or 'essential' ; and from the conditions of the first case, he derived several theorems concerning the functions defined by an implicit relation or by a differential equation of the first order.

These theorems are used in the study of the uniform integrals of a differential equation, as Painlevé showed in various applications, such as the finding of all the equations of the form $\frac{d u}{d z}=f(z, u)$, taking $f(z, u)$ as uniform, of which the general integral can be uniform. Finally, he discussed the various demonstrations of MittagLeffler's theorem and derived from it the important property that any holomorphic function in a convex area can be developed in that area as a series of polynomials. These and his other investi- 
gations became so well known that a few years later he was invited to give a course of lectures on his methods at the University of Stockholm.

At Stockholm, Painleve developed the remarkable theories which he published in 1897 as "Lecons sur la Theorie Analytique des Equations Differentielles", a masterly work closely following his "Conferences sur l'Integration des Equations de la Mécanique" published two years earlier. As is well-known, at Jacobi's death in the middle of last century, we had a complete method of treating partial differential equations of the first order involving one independent variable, or a system of such equations. There were considerable difficulties in the solution of equations of the second and of higher orders. True, there were the methods worked out by Laplace, Ampere and Darboux ; but rare were the instances when direct integration of such equations was possible. Following certain methods initiated by Cauchy in the calculus of limits, Painleve discovered several masterly solutions of these types of partial differential equations.

Painlevés treatment of equations of the second order with fixed critical points the integral of which contains algebraically one or two constants, or of equations of the second order with fixed critical points which are irreducible, opened up new vistas in a branch of higher mathematics illuminated by the labours of Riemann, MittagLeffler, Fuchs, Klein, Brioschi, Picard, Appell, Poincaré, Briot, Borel and others. Indeed, it is in this field that Painleve made his most important discovery, which won for him a seat in the French Academy of Sciences in 1900, when he solved, by means of a certain family of functions which have since been called by his name, certain types of differential equations which had puzzled two masters, Henri Poincare and Emile Picard. So great was Painlevé's fame as a mathematician at the time, that when the Grand Duke of Baden gave a reception to the members of the International Congress of Mathematics at Heidelberg in 1904, he was asking everyone introduced to him : "Could you show me M. Painleve ?"

Like all the scientific giants of his generation, Painlevé did not confine himself to pure mathematics. He soon applied his mastery of the calculus to various problems of mechanics, astronomy and the newly-born science of aerodynamics. The foundations of his treatment of applied mathematics is to be found in his "Conférences sur l'Intégration des Équations de la Mécanique" and his "Leçons sur le Frottement" as well as in the last portion of his "Leçons sur la Theorie Analytique des Équations Differentielles". Generally speaking, he follows the methods of Lagrange, Poisson, Hamilton, Jacobi, Legendre and Liouville; and with this classical tradition he was able to do much original work on the famous problem of three bodies and of $n$ bodies.

After the time of Lagrange, the problem of three bodies had been discussed by Poincaré, who laid the foundations of the new science of dynamical astronomy and won, incidentally, the inter- national prize offered by King Oscar II. With Picard, Charlier, Moulton, Levi-Civita and others, Paul Painlevé continued these researches, in which questions of stability had received much attention; for example, the stability of the solar system, which was affirmed by the eighteenth century astronomers, had been reopened by Weierstrass. It had been found that expressions for the coordinates of the planets do not converge, or converge for only a limited time. Poincaré discovered that some of the series which had been used to calculate the position of the bodies of the solar system are divergent. Would the ultimate divergence of these series, all other things being accounted for, throw doubt on the stability of the solar system and wreck its analytical representation?

With these premises, Poincare, Painlevé, LeviCività, Brown, Gylden and others, were busily engaged in determining the sufficient conditions for the stability of $n$ bodies in a dynamic system. Painleve, in particular, tried to determine the criteria in which the stability is made to depend upon that of a certain point transformation associated with the periodic function. His results have been used since for computing the perturbations of certain small planets. Further progress in the transformation and reduction of the $n$-body problem, in which the principal rôle has been played by the ten known integrals (the six integrals of motion of the centre of gravity, the three integrals of angular momentum and the integral of energy), is essentially related to the non-existence theorems of Bruns, Poincare and Painleve.

Celestial mechanics easily led Painleve to the study of aerodynamics; when the possibility of flying began to be discussed, he proved to have been something of a prophet. So early as 1906 he definitely stated as his opinion that heavier-thanair machines were a practical possibility. He was the first passenger of Wilbur Wright and flew with him at Auvours for the then record time of one hour and ten minutes. Painleve was similarly the first passenger taken up by Henry Farman at Mourmelon. $\mathrm{He}$ remained an enthusiast for aviation. Painlevé was the author of the first theory of sustentation in aviation, and did much pioneer work in the calculations involved in the construction of aeroplanes. He wrote two books on aviation; and published a part of the lectures he gave at the Faculty of Sciences in Paris as first holder of the "Chaire de Mecanique des Fluides et Applications" which was founded for him by the State. In these "Leçons sur la Résistance des Fluides non Visqueux" (1930), as well as in his "Cours de Mecanique" (1929) he develops many important views and results on the dynamics of continuous deformable media and on the theory of flying machines and aviation.

Perhaps it was his passion for applied mathematics which was at the root of Painlevé's philosophy of Nature. In his monograph "Les Axiomes de la Mécanique" (1922), where he discusses the assumptions of classical mechanics, the principle of causality, the postulates of relativity and the 
propagation of light, Painleve holds that the axioms of geometry themselves are expressions of actual properties of the natural bodies. At first, he was very cautious about Einstein's theory of relativity, and even presented a qualified criticism of Einstein's assumptions and conclusions at the Paris Academy of Sciences. During a public discussion on this subject at the Sorbonne in 1920, he dazzled his audience by the wealth of alternatives to Einstein's axioms he had discovered, and remained stubborn in his scepticism. The day was rainy, and I happened to offer the shelter of my umbrella to Prof. P. Langevin, the chief opponent of Painleve at the discussion. "After all," suggested Langevin, "I feel Painleve would be less obstinate after a good dinner!" A short time afterwards, in a preface written by Paul Painleve to my translation of Sir Arthur Eddington's lectures on relativity (1924), the great Frenchman acknowledged the profound value of the new picture of the universe, while in his "Cours de Mecanique", delivered at the Ecole Polytechnique, he gave a technical and searching discussion of Newtonian mechanics and Einstein's theories. It cannot be doubted, however, that Painlevé's criticism of the theory of relativity was instrumental in perfecting its details and in developing a clearer explanation of its implications as a new philosophy of Nature.

In appearance, Paul Painleve was a short and handsome man, sincere and straightforward, with an energetic face, but amiable ways and a kind heart. His life was as simple as it was strenuous. As he believed in doing all his work himself, all his time was taken up by his mathematical work, and his political and administrative duties. $\mathrm{He}$ had thus developed great power of concentration which I had an unexpected occasion of witnessing. I saw him during his last electoral campaign, and we were engaged in a discussion of the methods and issues of the elections, when Painleve had a telephone call : a colleague of his from the Sorbonne wanted some particulars about a mathematical problem. At once Painleve entered on a rapid and learned conversation on some esoteric parts of the tensor calculus. When he finished his argument, he apologised for the interruption and we carried on our political conversation.

Such was the man whom legend had annexed even during his lifetime. His absent-mindedness, for example, was a source of amusement in France and among his friends. He would often take a taxi home when his own car was waiting for him ; or again, give his telephone number to the taxi-driver asking for his address. On one occasion, expecting a friend, he left a note on his door : "Painleve will be back in fifteen minutes." Returning to his house, he saw his own note and waited on the step for his own return! But now Painleve is no more. His example, his spirit and his work will, however, live for ever in the hearts and minds of his innumerable disciples and colleagues, who mourn with France and with the scientific world the great memory of the 'President'.

Thomas Greenwood.

WE regret to announce the following deaths :

Mr. Donald J. Armour, C.M.G., surgeon to the National Hospital for Nervous Diseases, president of the Medical Society of London in 1929-30, and of the Association of British Neurological Surgeons in 1930-32, an authority on brain and spinal surgery, on October 23, aged sixty-four years.

Sir George Makins, G.C.M.G., C.B., president of the Court of Exammers of the Royal College of Surgeons since 1917, formerly dean of St. Thomas's Hospital Medical School, on November 2, aged seventy-nine years.

Dr. Emile Roux, For. Mem. R.S., director of the Pasteur Institute in 1904-18, known for his work in bacteriology in collaboration with Pasteur and Behring, on November 3, aged eighty years.

Mr. F. H. Stevens, formerly a mathematics master at Clifton College, author and part-author of numerous well-known textbooks of mathematics, on November 1, aged eighty years.

\section{News and Views}

\section{Royal Society Medal Awards}

His MaJesty THE KING has approved of the following awards this year by the president and council of the Royal Society in respect of the two Royal medals :-Royal medal to Prof. G. I. Taylor, Yarrow research professor, Cambridge, for his mathematical work in physics, geophysics and aerodynamics; and Royal medal to Mr. P. P. Laidlaw, pathologist to the Medical Research Council, for his work on diseases due to viruses, including that on the cause and prevention of distemper in dogs. The following awards of medals have also been made:-Copley medal to Prof. Theobald Smith, director of the Department of Animal Pathology in the Rockefeller Institute, Princeton, for his original research and observation on diseases of animals and man; Davy medal to
Dr. W. H. Mills, University lecturer in organic chemistry in the University of Cambridge, for his researches in organic chemistry, and for his work on the syntheses and properties of the cyanine dyes, and more especially for his investigation of novel types of asymmetric molecules; Hughes medal to Prof. E. V. Appleton, Wheatstone professor of physics in King's College, London, for his researches into the effect of the Heaviside layer upon the transmission of wireless signals.

\section{Officers and Council of the Royal Society}

THE following is a list of those recommended by the president and council for election to the council of the Royal Society at the anniversary meeting on November 30 :-President: Sir Frederick Gowland Hopkins; Treasurer: Sir Henry Lyons; Secre- 